\title{
$\mathrm{ACL}$ 알고리즘을 이용한 자동차 번호판 영역 추출에 대한 연구
}

\author{
장 송 주 ${ }^{\dagger}$ 신 병 철 ${ }^{\dagger}$
}

요 약

\begin{abstract}
자동차 번호판 인식 시스템에서 가장 중요한 요소는 자동차 이비지로부터 번호반 영역울 정확히 검출해 내는 것이다. 자동차 이미지에서 번 호판 영역을 추출하기 위한 방법으로 색상과 밝기 정보와 자동차 번호판의 가로 : 세로 비율 등 번호판을 인식할 수 있는 정보를 혼용한 $\mathrm{ACL}$ 알고리츰을 제안한다. ACL 알고리즘을 사용함으로써 기존의 색상 성보나 명암 정보 만울 이용할 경우 자동차 번호판 영역 추출이 잘되지 않는 문제를 해소시켜 준다. 본 논문에서 제안하는 $\mathrm{ACL}$ 알고리즘은 자눙차 이미지에서 번호판 영역을 추출하기 위하여 색상 정보와 명암 정보, 기 타 자동차 번호판을 판단할 수 있는 정보를 모두 이용한다. ACI. 알고리즘을 이용하여 번호판 추출 실험을 한 결과 $97 \%$ 의 추출률을 보였다. $\mathrm{ACL}$ 알고리즘을 이용하여 추출된 번호판을 이용하여 문자 영역, 분자 인식을 실험한 결과 $92 \%$ 의 결과를 보였다.
\end{abstract}

\section{A Study on Car License Plate Extraction using ACL Algorithm}

\author{
Seung Ju Jang ${ }^{\dagger} \cdot$ Byoung chul Shin ${ }^{\dagger}$
}

\begin{abstract}
In recognition system of the car license plate, the most important is to extract the image of the license plate from a car image. In this paper, we use ACL (Adaptive Color Luminance) algorithm to extract the license plate image from a car image. The ACL algorithm that uses color and luminance information of a car image is used to extract the image of the license plate. In this paper, color, luminance and other related information of a car image are used to extract the image of the license plate from that of a car. In this reason, we call it the ACL algorithm. The ACL algorithm uses color, luminance information and other related information of a license plate. These informations are avaliable to exact the image of the license plate. The rate of extracting the image of the license plate from a car is $97 \%$. The experimental result of the $\mathrm{ACL}$ algorithm for the character region is $92 \%$.
\end{abstract}

키워드 : ACL(Adaptive Color-Luminance), 알고리즘, 색상 분석(Color Analysis), 명암 분석(Luminance Analysis), 번호판 영역 추출 (Car License Plate Extraction)

\section{1. 서 론}

최근들어 정보 통신 분야의 급속한 기술 확산으로 인하 여 자동 인식 시스텝 분야의 기술이 중요한 부분으로 대두 되기 시작하고 있다. 특히 자동차 번호판 자동 인식 시스템 은 우리의 일상 생활에 활용 가치가 높다. 번호판 자동 인 식 시스템은 주차장 관제 시스템, 통행 요금 징수, 교통량 조사, 버스 전용 차로 위반 등과 같은 시설의 자동화에 크 게 기여할 수 있는 분야이다[1-3].

많은 국가에서 자동차 번호판을 자동으로 인식하기 위한 작업에 박차롤 가하고 있다. 그러나 많은 연구에도 불구하 고 인식률이 그리 떠어난 연구 결과들이 발표되고 있지 못 하다. 대부분의 연구 접근 방식이 특정한 상황에만 맞도록 되어있는 알고리즘을 사용하는 획일적인 방식을 채택하고

* 본 연구는 과학기술부 · 한국과학재단 지정 부산광역시 지원 시역협력연구 센터인 농의대학표 전자세라믹스연구센터의 지원에 의하 것입니다.

$\dagger$ 정 회 원: 당의대학표 컴퓨터공학과 iㅛㅅㅜ

†† 정 회 원 : 동의대학교? 신소재공학과 교수 논문접수 : 2002 년 4 월 3 일, 심사완표 : 20002 년 11 월 6 일
있고 특정한 환경에 유리한 방법들을 적용하는 것으로 그 치고 있다. 이러한 예로 자동차 번호판 인식에 신경망 알고 리즘을 많이 채택하고 있다.

실용적인 번호판 인식 시스템 개발에 있어서 중요한 부 분은 두가지로 요약할 수 있다. 첫 번째는 번호판 영역을 정확히 추출하는 것이고 둘째는 추출된 번호판 영역을 가 지고 문자 및 숫자를 인식하는 것이다.

국내에서 자동차 번호판에 대한 연구는 1980년대 말부터 본격적으로 이루어졌다. 이치화를 동해 윤곽선을 검출한 이 진 영상에서 허프 변환(Hough transform)으로 번호판의 수 직.수평 경계선을 검출하는 방법[6,15-17], 명암 값의 변화에 의한 숫자 영역을 검출한 후 번호판 영역으로 확대해 나가는 방법[1,2], 명암 값의 편차가 많은 부분을 대상으로 허프 변 환을 이용하는 방법[2,3], 히스토그램 정규화 과정을거쳐 이 치화하고 숫자 영역을 검출하는 방법[4,5, 9-11]등이 있다. 또 한 투영(Projection)에의한 방법, 원형 정합(template matching)에의한 방법, 영역 분할에의한 방법, 명암도 변화롤 이용 한 방법 등이 있다[2,7-9,12-14]. 허프 변환으로 번호판의 
수직, 수평 성분을 추출하는 방법은 메모리의 양과 허프 변 환에 처리시간이 많이 소요된다는 단점이 있다.

기존의 연구 결과들은 제한된 문제들에 대한 지엽적인 해결 방안들을 제시하고 있다. 이러한 예로 자동차 번호판 인식에서 정상적이지 않은 번호판인 경우가 대부분이라는 것이다. 그러나 자동차 번호판 인식에서 정상적인 경우가 $95 \%$ 이상이고 이와 같이 비정상적인 경우가 $5 \%$ 도 안되는데 이 $5 \%$ 도 안되는 경우를 위한 문제가 전부인 것처럼 문제 접근을 하고 있다는 것이다.

대부분 자동차 번호판 인식 시스템은 크게 자동차 번호 판 영역 추출과 인식과정으로 나눈다. 정확한 자동차 인식 을 위하여 가장 먼저 선행되어야 하는것이 자동차 번호판 영역의 정확한 추출이다. 이것은 번호판 영역을 추츨하는 것이 번호판 추출 후 문자, 숫자를 인식하는 것보다 어렵고 중요하기 때문이다.

본 논문은 기존 연구의 이러한 문제점을 해결하기 위하여 $\mathrm{ACL}$ (Adaptive Color Luminance) 알고리즘을 제안한다. ACL 알고리즘은 자동차 이미지에서 색상 정보, 명암 정보, 기타 자동차 번호판 영역을 판단할 수 있는 모든 정보를 이용하 여 정확한 자동차 번호판 영역을 추출한다. 즉, 한가지 방법 으로 자동차 번호판 영역을 추출하는 것이 아니라 여러 가지 방법을 종합적으로 이용하여 자동차 번호판 영역을 추출한 다. 본 논문에서 제안하는 알고리즘을 $\mathrm{ACL}$ 알고리즘이라고 부른다. 물론 기존의 자동차 번호판 인식을 위한 방법으로 명암과 색상 정보를 이용한 방법들이 있다 [2]. 그러나 이러 한 방식들은 자동차 번호판 영역이 아닌, 자동차 번호판 영 역 내에 존재하는 문자를 바로 찾아내는 방식을 취하고 있 다. 이러한 방식의 문제점은 자동차 번호판 영역이 아닌 다 른 영역에 존재하는 문자를 자동차 번호판 문자로 오인할 가능성이 있다는 것이다. 본 논문에서 제안하는 $\mathrm{ACL}$ 알고 리즘은 명암, 색상 정보 뿐만아니라 자동차 번호판의 가로 : 세로 비 둥 자동차 번호판 영역을 판단하는 데 필요한 모든 정보를 동원하여 오류가 발생할 가능성을 줄인다.

본 논문의 구성은 다음과 같다. 2 장에서는 $\mathrm{ACL}$ 알고리 즘을 이용한 번호판 추출, 3 장에서는 $\mathrm{ACL}$ 알고리즘을 이용 한 실험 및 결과 분석, 마지막으로 4 장에서는 결론에 대해 서 언급한다.

\section{ACL(Adaptive Color-Luminance) 알고리즘을 이용 한 번호판 추출}

자동차 번호판 인식 시스템에서 가장 중요한 것은 번호 판 영역의 추출을 통한 자동차 번호판 인식의 정확도를 높 이는 것이다. 따라서 자동차 번호판 인식 시스템의 출발점 은 자동차 번호판 영역을 정확히 추출하는 것이다. 자동차 번호판 영역을 정확히 추출하기 위해서는 자동차 번호판 영역에 대한 정보롤 최대한 활용해야 한다. 자동차 번호판
영역에 대한 특징을 이용하여 이 정보를 최대한 활용한다.

차량 번호판은 크기별, 차종별, 용도별로 구분된다. 크기 별로는 소형, 보통, 대형으로 구분되고, 차종별로는 승용차, 승합차, 화물차 및 특수차로 분류된다. 용도별로는 사업용, 비사업용 및 외표관 차로 구분된다[1,2].

자동차 번호판의 색상은 차랑의 용도에 따라 배경, 문자 및 테두리 색상이 결정된다. 기존 연구들에서는 이러한 특 징을 이용하여 번호판을 판별하는 기준으로 사용하여 왔다. 특히 번호판의 가로 세로비는 약 $2: 1$, 번호판 영역의 배경 영역과 문자 영역의 비는 약 $7: 3$ 이라는 사실에 바탕을 두 고 번호판 추출 작업을 하는데 이용되어 왔다.

자동차 번호판의 위와 같은 성질을 최대한 이용하고 부 가적으로 활용할 수 있는 정보롤 최대한 사용한다. 자동차 영상을 바이너리 이미지로 변환했을 경우는 밝은 바탕에 어두운 글자, 어두운 바탕에 밝은 글자의 두 가지 타입 중 하나로 만들어진다. 이러한 특징들을 최대한 활용한다. 본 논문에서 제안한 $\mathrm{ACL}$ 알고리즘을 적용하기 위하여 실제 주차장 등에 설치된 카메라를 통해서 자동차 번호판 데이 터를 읽어들일 수 있는 모듈을 설계하였다.

자동차 이미지에서 자동차 번호판 영역을 추출하는 $\mathrm{ACL}$ 알고리즘은 먼저 자동차 번호판 영역 $(\mathrm{X} 1, \mathrm{Y} 1),(\mathrm{X} 2, \mathrm{Y} 2)$ 이 라고 판단되는 영역에 대해서 색상 정보를 이용하여 구한 다. 다음으로 자동차 이미지에서 명암 변화 정보를 이용하 여 번호판 영역이라고 판단되는 좌표 $\left(\mathrm{X}^{\prime}, \mathrm{Y}^{\prime}\right),\left(\mathrm{X} 2^{\prime}, \mathrm{Y}^{\prime}\right)$ 를 구한다. 구해진 좌표값을 이용하여 정확한 위치 좌표를 찾기 위한 판단 작업을 하게 된다. 판단 작업을 할 경우 앞 에서 구한 $(\mathrm{X} 1, \mathrm{Y} 1),(\mathrm{X} 2, \mathrm{Y} 2)$ 좌표와 $\left(\mathrm{X} 1^{\prime}, \mathrm{Y} 1^{\prime}\right),\left(\mathrm{X} 2^{\prime}, \mathrm{Y}^{\prime}\right)$ 좌표와 기타 번호판 영역 판단을 위한 자료를 종합하여 정 확한 번호판 위치 좌표 $\left(\mathrm{X} 1^{\prime \prime}, \mathrm{Y} 1^{\prime \prime}\right),\left(\mathrm{X} 2^{\prime \prime}, \mathrm{Y} 2^{\prime \prime}\right)$ 를 구한다.

\section{1 번호판 영역 추출을 위한 색상 분석}

자동차 번호판 영역을 추출하기 위하여 가장 먼저 선행 되는 과정이 번호판이 존재하리라고 예상되는 지점을 찾는 것이다. 이것은 자동차 번호판 색상에 의하여 판단한다. 자 동차 번호판은 차종별, 용도별로 섹상을 달리하지만 이 색 상은 일정하게 정해져 있다. 따라서 이러한 색상을 갖는 부 분에 대한 판단으로 번호판 좌표값을 얻는다.

본 논문에서는 자가용을 대상으로 실험을 하였다. 자가용 은 녹색바탕에 흰색 글씨로 되어 있다. 따라서 이 두 색깔 로 되어 있는 영역의 좌표값을 먼저 찾는다.

번호판 영역이 존재하는 후보 영역을 찾을 때 정확히 녹 색 영역을 찾을 경우 번호판 영역의 반사나 다른 원인에 의 하여 녹색이 변조되어 나타나는 경우는 찾지 못하는 경우가 발생할 수 있다. 따라서 번호판 영역에 대한 색상에서 허용 오차값을 주어서 이 허용 오차 범위내에 둘어갈 경우는 번호 판 영역으로 판단을 하게 된다. 이 허용 오차값은 $\mathrm{a}(\mathrm{a}$ 는 전 체 색상 정보 범위의 $\pm 2 \%$ 내외)로 값을 설정하였다. 


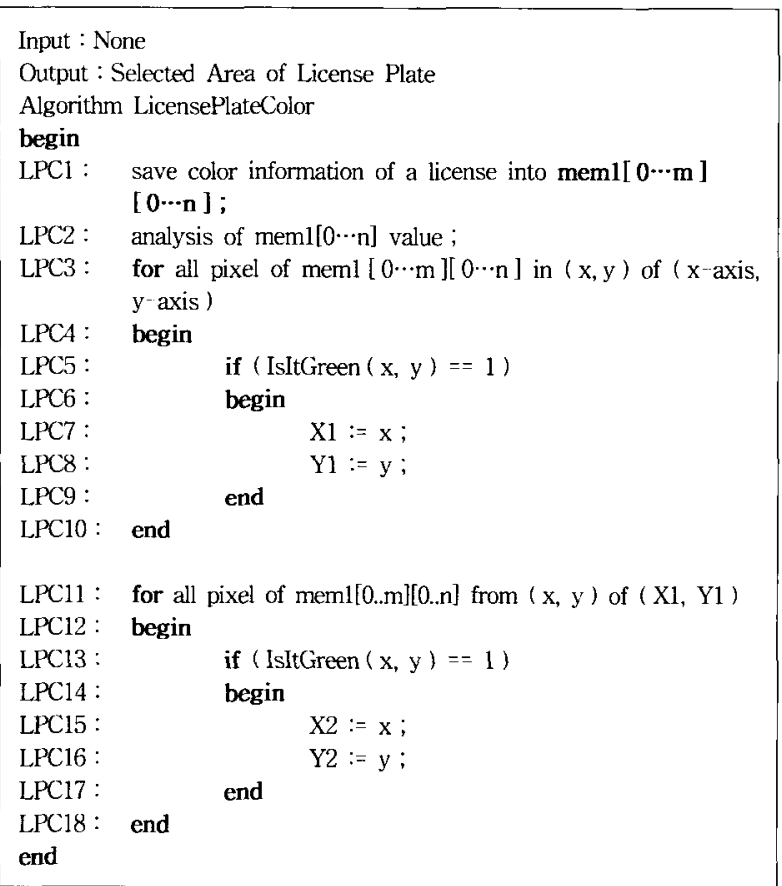

(그림 1) 번호판 영역 추출을 위한 색상 분석

(그림 1)은 자동차 이미지에서 자동차 번호판 영역울 찾아 내는 알고리즘이다. 먼저 원래 자동차 이미지 정보를 meml 에 저장을 한다(LPC1 문장). meml 배열에 저장된 정보릅 분석한다(LPC2 문장). 자동차 번호판 영역에 대한 좌표값 (X1, Y1), (X2, Y2)를 찾는다(LPC3문장에서 $\mathrm{LPC18}$ 문장). 이 좌퐈값이 자동차 번호반이 존재하는 영역이다.

\section{2 번호판 영역 추출을 위한 명암 변화}

기본적으로 선행되어야 할 것이 자동차 번호판 영역을 정확히 추출해 내는 것이다. 자동차 번호판 영역을 추출하 기 위한 방법 중 하나로 자동차 이미지 중에 자동차 번호 판 영역에 대한 명암 변화 정보를 이용한다. 자동차 번호판 색상 중에서 번호판 영역에 대한 명암 변화 정보는 자동차 이미지 중에서 번호푠 영역의 특성이 명암 변화가 급격하 게 일어난다는 것에 착안한 것이다. 추출된 명암 정보는 특 정한 배열에 저장을 하여 둔다.

자동차 이미지 명암 변화 정도를 저장해 놓은 배열에 대 해서 분석 작업을 수행한다. 명암 변화를 분석한다. 데이타 분석은 일정한값 이상 차이가 나는 부분에 대한 좌표값 $(\mathrm{X} 1, \mathrm{Y} 1),(\mathrm{X} 2, \mathrm{Y} 2)$ 을 기억한다. 이 좌표 값들 중 일정한 거 리(d) 내에 존재하는 좌표값들은 연속된 좌표값의 범위 내 에 있는 것으로 판정한다. 이렇게 하는 이유는 번호판 영역 중에서 명암 변화가 심하게 일어나서 잘못된 좌표값을 가 지고 번호판 영역을 찾는 경우를 방지하기 위함이다. 명암 정보롤 이용한 자동차 번호판 영역 추출 알고리즘은 다음 과 같다.

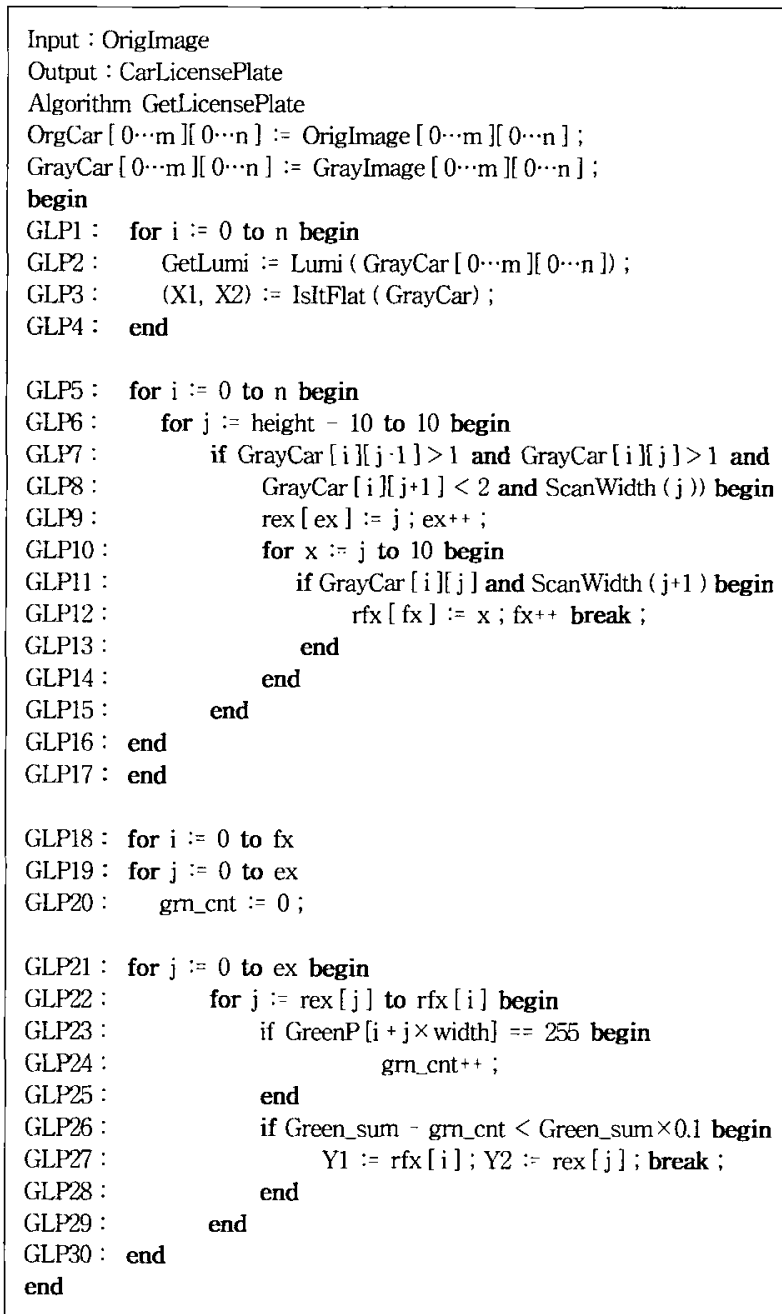

(그림 2) 자동차 번호판 영역을 얻기 위한 알고리즘

(그립 2)는 자동차 번호판 영역을 얻기 위한 알고리즘을 보 여준다. 먼저 자동차 이미지에서 밝기 정보를 이용하여(GLP2) 자동차 번호판 영역이라고 판단되는 곳(GLP3)을 찾는다. 이 과정에서 $\mathrm{X}$ 축의 $(\mathrm{X} 1, \mathrm{X} 2)$ 좌표를 얻는다. 다음으로 녹색 이라고 판단되는 지역을 찾는다(GLP5-GLP17). 녹색 영역 이라고 판단되는 지역의 좌표값을 $\mathrm{rex}, \mathrm{rfx}$ 배열에 저장한 다. rex, $\mathrm{rfx}$ 값의 좌표 범위 내에서 녹색 값의 시작 위치와 끝나는 위치의 좌표값 (Y1, Y2)를 구한다(GLP21-GLP30).

\section{3 번호판 추출을 위한 $\mathrm{ACL}$ 알고리즘}

번호판 영역의 안정적인 추출은 실제적인 번호판 인식 시스템 개발에 있어서 중요한 단계이다. 기존 연구들은 대 부분이 신경망을 이용한 번호판 영역 추출에 초점이 맞추 어져 있다 $[1,12]$. 신경망을 이용하는 경우는 자동차 번호판 에 이물질이나 오류가 있을 경우 데이타 복구를 위한 방법 으로 많이 이용될 수 있다. 신경망 방식은 근본적으로 수행 속도가 너무 느리기 때문에 자동차 번호판과 같은 정형화 된 이미지를 처리하는 일반적인 환경에는 적합하지 않다. 
본 논문에서는 자동차 번호판 영역 추출의 정확도를 높 일 수 있는 방법으로 한 가지 방법에 의한 자동차 번호판 영역을 인식하지 않고 두 가지 이상의 방법을 조합하여 보 다 정확한 자동차 번호판 영역을 추출한다. 자동차 번호판 영역을 추출하는데 사용하는 방법은 먼저 번호퐌 영역에 대한 색상 분석 작업을 수행한다. 색상 분석 작업에 의하여 구해진 좌표 값 $(\mathrm{X} 1, \mathrm{Y} 1),(\mathrm{X} 2, \mathrm{Y} 2)$ 를 기억해 둔다. 또 다른 방법으로 자동차 번호판을 이진화(binary)시켜서 색상 정보 중 명암 변화값을 구한 다음 이 명암 변화가 현격히 발생 되는 지점을 자동차 번호판 좌표값 $(\mathrm{X} 3, \mathrm{Y} 3),(\mathrm{X} 4, \mathrm{Y} 4)$ 으로 기억한다. 자동차 번호판의 이진화 방법은 원래의 색상 정 보를 여기에 상응하는 흑/백의 값으로 연결지어서 이진화 색상 정보를 구한다. 이렇개 구해진 이진화 정보를 이용하 여 명암 변화 값으로 사용한다. 이처럼 구해진 좌표값을 이 용하여 어느 좌표 영역이 번호판 영역인지를 찾아낸다. 번 호판 영역의 구별은 두 가지 방법으로 구한 좌표값 영역에 대해서 색상 정보(histogram)를 이용한 분석과 가로와 세로 길이의 비가 $2: 1$ 어느쪽에 가까운지 등을 통하여 번호판 영역을 찾아낸다. 이러한 판단을 통하여 정확한 번호판 영 역에 가까운 좌표를 결정한다.

원래 자동차 번호판 영역에 대한 이미지 정보를 OrgRect 배열에 저장한다. 원래 자동차 번호판 이미지 정보에서 gray 값으로 변환하여 GrayRect 배열에 저장한다. gray 값을 가지 고 바이너리 이미지 데이타 값을 산출하여 BinaryRect 배열 에 저장한다.

자동차 이미지 정보를 이용하여 원래 이미지 정보를 저 장하고 이 정보를 이용하여 바이너리 이미지 파일을 만들 고 이 두 개의 정보를 이용하여 자동차 번호판 영역을 추출 한다. 자동차 번호판 영역을 추출하기 위한 과정에서 원래 이미지 정보롤 이용하여 (X1, Y1), (X2, Y2) 좌표를 구한다. 그리고 바이너리 이미지 정보를 이용하여 $\left(\mathrm{X} 1^{\prime}, \mathrm{Y} 1^{\prime}\right),\left(\mathrm{X} 2^{\prime}\right.$, $\mathrm{Y}^{\prime}$ ) 좌표를 구한다. 이렇게 구해진 좌포값을 가지고 정확 한 좌표를 구하기 위하여 자동차 번호퐌과 관련한 정보롤 이용한 검증 작업을 하게 된다. 이러한 검증 작업후 최종적 으로 (X1", $\left.\mathrm{Y} 1^{\prime \prime}\right),\left(\mathrm{X} 2^{\prime \prime}, \mathrm{Y} 2^{\prime \prime}\right)$ 좌표를 구한다.

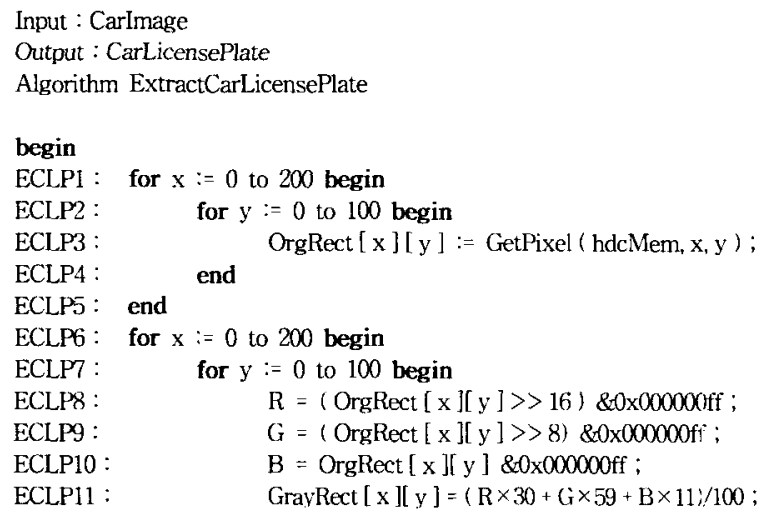

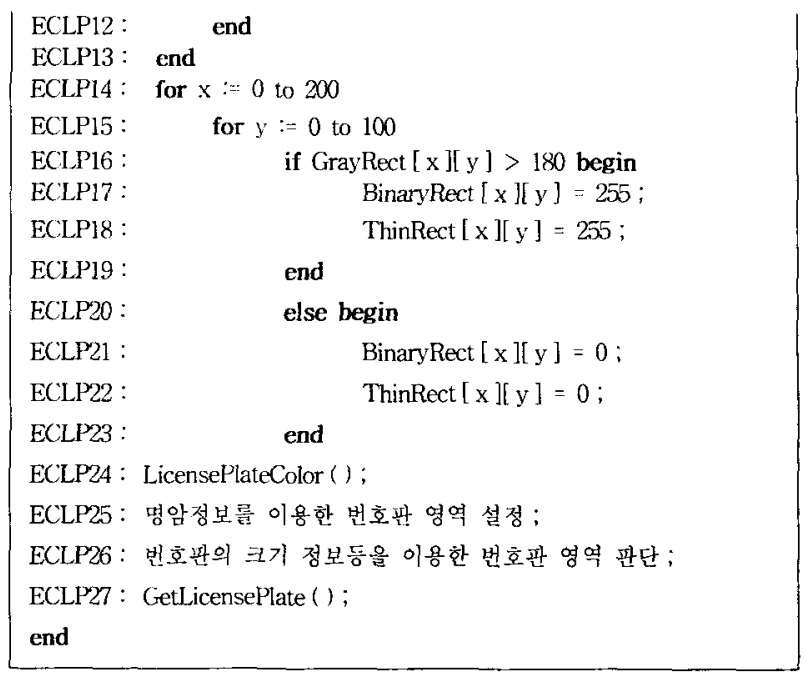

(그림 3) 번호판 영역 추출을 위한 $\mathrm{ACL}$ 알고리즘

(그림 3)에서 원래 자동차 번호판 영역에 대한 이미지 정 보를 OrgRect 배열에 저장한다 (ECLP1-ECLP5), 원래 자 동차 번호판 이미지 정보를 이용하여 gray 값으로 변환하여 GrayRect 배열에 저장한다(ECLP6-ECLP13). gray 값을 가 지고 바이녀리 이미지 데이타 값을 산출하여 BinaryRect 배 열에 저장한다(ECLP14-ECLP23). 자동차 이미지 정보폴 이용하여 원래 이미지 정보를 저장하고 이 정보를 이용하여 바이너리 이미지 파일올 만들고 이 두 개의 정보를 이용하 여 자동차 번호판 영역을 추출한다. 자동차 번호판 영역을 추출하기 위한 과정에서 원래 이미지 정보를 이용하여 (X1, $\mathrm{Y} 1),(\mathrm{X} 2, \mathrm{Y} 2)$ 좌표를 구한다. 그리고 바이너리 이미지 정보 를 이용하여 $\left(\mathrm{X}^{\prime}, \mathrm{Y}^{\prime}\right),\left(\mathrm{X} 2^{\prime}, \mathrm{Y} 2^{\prime}\right)$ 좌표를 구한다. 이렇게 구해진 좌표값을 가지고 정확한 좌포를 구하기 위하여 자동 차 번호판과 관련한 정보를 이용한 검증 작업을 하게 된다. 이러한 검증 작업 후 최종적으로 $\left(\mathrm{X} 1^{\prime \prime}, 1^{\prime \prime}\right),\left(\mathrm{X} 2^{\prime \prime}, \mathrm{Y} 2^{\prime \prime}\right)$ 좌표 를 구한다(ECLP24-ECLP27).

\section{3. 실험 및 결과 분석}

본 논문에서 제안한 번호판 인식 방법에 대한 인식률 및 성능 평가를 위하여 다양한 상태의 차량 이미지 정보를 가지 고 실험을 수행하였다. 차량 영상의 입력을 위하여 $\mathrm{CCD}$ 카 메라로부터 입력되는 데이타률 처리하도록 되어 있다. 그러 나 실험의 편의를 위하여 디지털 카메라로부터 입력 영상을 받아들여서 이 데이타를 가지고 이미지 처리를 수행하였다.

입력 영상의 해상도는 $640 \times 480$ 화소의 크기와 256 칼라 색상을 가진다. 그리고 실험을 위해 사용된 컴퓨터는 팬티엄 표이다. 실험의 편의를 위하여 모든 차량에 대해서 하지 않고 개인용 차량을 중심으로 수행하였다. 그리고 실제 자동차 번 호퐌 영상의 입력을 위한 카메라 설치 환경이 되지 않아 자 동차 번호판 영상의 입력을 인위적으로 수행하였다. 이 영상 이미지를 가지고 자동차 번호판 인식 작업을 수행한다. 입력 
영상에서 자동차 번호판 영상의 크기는 약 $7 \times 3.5$ 정도이다.

차량 이미지에서 번호판 영역을 추출한는 과정, 추출된 번호판에서 문자를 인식하는 과정은 (그림 4)와 같다.

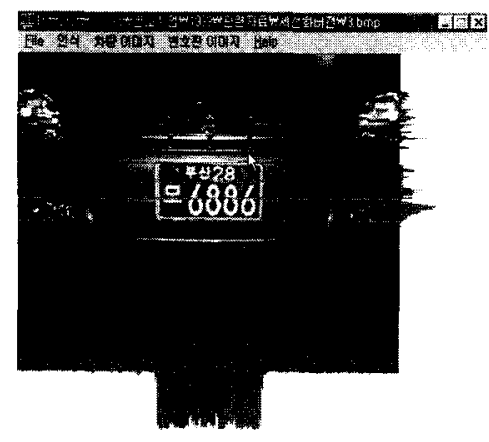

(a) 프로그램 수행 화면

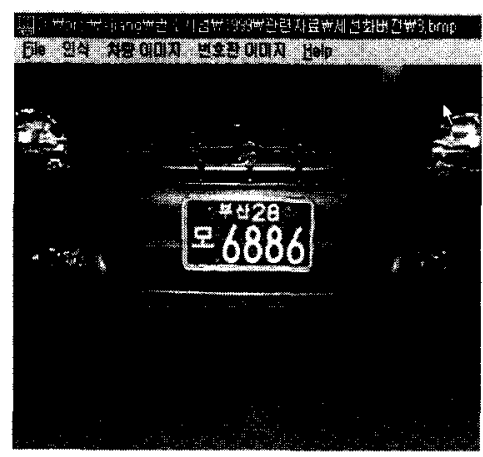

(b) 명암 변화 추출 결가

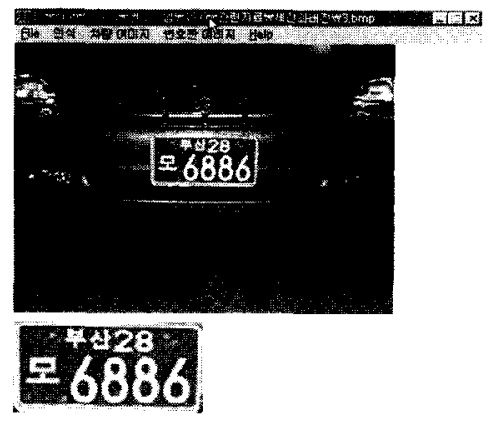

(c) 번호반 영역 추출 결과

(그림 4) 자동차 번호판 추출

(그립 4)은 본 논꾼에서 제안한 $\mathrm{ACL}$ 알고리즘을 실제 $\mathrm{VC}++$ 언어를 사용하여 자동차 번호판을 추츨하는 과정이 다. (그림 4$)(a)$ 는 자동차 번호판이 있는 차량의 사진이다. (그림 4$)(\mathrm{a})$ 의 이미지를 입력으로 받아둘여서 이 이미지릅 이용하여 $\mathrm{ACL}$ 알도리즘은 색상, 명암과 기타 자동차 번호 판 영역을 판단하는데 필요한 정보를 이용하여 번호판 영 역을 추출하는 과정을 거친다((그림 4)(b)). (그립 4)(b)그림 에서 가포축과 세포축에 나타나 있는 그래프는 ACL 알고 리즘을 수행한 후 색상과 명압 정보를 이용하여 자동차 번 호판 영역이라고 추측되는 영역에 대해서 표시가된 것이다.
가로축과 세로축의 이 정보를 이용하여 자동차 번호판 영 역을 찾게된다((그림 4$)(c))$.

<표 1>은 위의 (그림 4)과 같이 $\mathrm{ACL}$ 알고리즘을 이용하 여 자동차 번호판 영역을 추출한 결과를 보여주고 있다. 먼 저 대상 영상 수는 150 개로 하였다. 150개 데이터는 주차관 제 시스템에서 카메라를 이용하여 주차장에 들어오는 차량 의 자동차 번호판을 촬영한 사진이다. 150 개의 영상에 대해 서 색상 정보만을 이용하여 번호판 영역을 추출한 경우(< 표 1>(1)), 명암 정보만을 이용하여 번호판 영역을 추출한 경우(<표 1>(2)), $\mathrm{ACL}$ 알고리즘과 같이 자동차 번호판을 판단할 수 있는 모든 정보를 이용한 경우(<표 1>(3)) 등이 다. <표 1>의 결과에서 대상 영상수는 150 이다. 150 개의 영상 중에서 색상 정보만을 가지고 번호판 영역을 추출했 을 경우 150 개 중 78 개만 번호판 추출이 가능했다. 명암 변 화를 이용한 경우 150 개 충에서 95 개 번호판 추출이 가능 했다. ACL 알고리즘을 이용한 경우 150 개 중에서 146 개의 번호판 추출이 가능했다.

〈표 1〉명암 및 색상 정보를 이용한 번호판 인식

\begin{tabular}{|c|c|c|c|}
\hline & 대상 영상 & 정추출 영상수 & 추츌률(\%) \\
\hline \hline $\begin{array}{c}\text { (1) 색상 정보를 } \\
\text { 이용한 경우 }\end{array}$ & 150 & 87 & 58 \\
\hline $\begin{array}{c}\text { (2) 명암 변화플 } \\
\text { 이용한 경운 }\end{array}$ & 150 & 116 & 77.3 \\
\hline $\begin{array}{c}\text { (3) ACL 알고리즘을 } \\
\text { 이용한 경우 }\end{array}$ & 150 & 146 & 97 \\
\hline
\end{tabular}

<표 2>는 추출된 번호판 영역에서 "부산 28 모 6886 "과 같은 문자 영역 인식에 대한 실험 결과를 보여준다. 〈표 2> 의 결과에서 ACL 알고리즘울 이용한 번호판 영역을 추출하 는데 $97 \%$ 의 효과롤 보였다(<표 1>(3) 경우와 동일). 정상적 으로 추출된 번호판 영역에서 $\mathrm{ACL}$ 알고리즘을 이용하여 문 자 영역을 추출하는데 전체 영상 수 대비 $95 \%$ 의 추출률을 보였다. 추출된 문자중에서 문자 인식률은 전체 영상수 대비 $92 \%$ 의 인식툴을 보였다.

〈표 2〉 문자 영역 추출 및 인식 결과 실험

\begin{tabular}{|l|c|c|c|}
\hline & 대상영상 & 정추술 영상수 & $\begin{array}{c}\text { 단계별 추출률 } \\
\text { /최종인식률(\%) }\end{array}$ \\
\hline \hline 번호판 추출 & 150 & 146 & 97 \\
\hline 분자영역 추훌 & 146 & 142 & $97 / 95$ \\
\hline 분자 인식 & 142 & 138 & $95 / 92$ \\
\hline
\end{tabular}

\section{4. 결 론}

본 논꾼은 자동차 번호판 인식을 위한 번호판 추출 알고 리즘으로 ACL 알고리즘을 제안했다. 기존의 자동차 이미지 에서 자동차 번호판 영역 추출을 위한 방법으로 여러가지 기법 들이 있다. 이러한 여러 가지 알고리즘울 이용한 번호 
판 인식률도 특수한 데이타에 대한 특수한 환경 중심으로 이루어지고 있다는 것이다.

본 논문에서 제안한 $\mathrm{ACL}$ 알고리즘은 자동차 이미지에서 자동차 번호판 영역을 추출하기 위한 알고리즘이다. 자동차 이미지에서 자동차 번호판 영역 추출을 위하여 색상 정보, 자동차 이미지에서 명암 변화 정보, 자동차 번호판의 크기 정보, 번호판의 면적 정보등을 이용하여 자동차 번호판을 추출한다. 본 논문에서 제안한 $\mathrm{ACL}$ 알고리즘은 한 가지 방 법으로 번호판 영역을 추출하는데 따른 문제점을 보완하기 위한 것이다. $\mathrm{ACL}$ 알고리즘은 자동차 이미지에서 자동차 번호판을 추출하기 위하여 색상, 밝기, 자동차 번호판의 크 기 정보를 종합하여 번호판 추출을 위해서 사용한다.

본 논문에서 제안한 $\mathrm{ACL}$ 알고리즘을 사용하여 자동차 번호판 영역 추출을 위한 실험 결과에서 색상 정보나 명암 정보등과 같은 하나의 요소를 가지고 번호판 영역을 추출 했을 경우보다 번호판 영역을 추출할 수 있는 가능성이 $97 \%$ 로 횔씬 우수함을 알 수 있었다.

그리고 $\mathrm{ACL}$ 알고리즘을 이용하여 추출된 번호판 영역 이미지를 이용하여 문자 영역을 추출하고 추출된 문자 영 역 이미지를 이용하여 문자 인식을 하게 된다. 문자 인식 결과 전체 자동차 번호판 이미지에 대해서 $92 \%$ 정도의 인 식이 이루어짐을 알 수 있었다.

앞으로 자동차 번호판 이미지에 대해서 번호판 영역을 추출하고 추출된 번호판에서 문자를 추출한 후 문자 인식 을 하는 부분에 이르기까지 인식률과 추출률의 향상을 위 해 자동차 번호판을 판단할 수 있는 정보의 추가와 $\mathrm{ACL}$ 알고리즘을 개선하는 쪽으로 연구롤 진행할 것이다.

\section{참 고 문 헌}

[1] 김숙, 조형기, 민준형, 최종욱, “명암벡터를 이용한 차턍번호 판 추출 알고리즘”, 한국정보과학회논문지(B), 제 25 권 세 4 호, 1998.

[2] 김병기, "명암변화와 칼라 정보를 이용한 차랑 번호판 인식", 정보처리학회, 제6권 제12호, 1999.

[3] 이진수, 권오준, 방승양, "개선된 자소 인식 방법을 통한 고인 식률 인쇄체 한글 인식”, 한국정보과학회논문지(B), 제23권 제8호, 1996.

[4] 김의정, 김태균, “오프라인 문서에서 개별 문자 추출과 한자 인식에 관한 연구”, 정보처리논문지, 제4권 제5호, 1997.

[5] 김의정, 김태균, "최대 블록화 방법을 이용한 문자획 특징 추 출에 관한 연구”, 정보처리논문지, 제4권 제4호, 1997.

[6] 조동욱, "화상 구조 파악에 의한 화상의 잡음 제거 및 격계선 추출”, 정보처리논문지, 제4권 제7호, 1997.

[7] 곽후근, 김성호, 정규식, "한글 문자의 구조 정보에 기반한 동 적 정보 복원", 한국정보과학회논문지, 제25권 제3호, 1998.

[8] 박희선, 이성환, “오프라인 글씨 인식을 위한 은넉 마르코프 메쉬 랜덤 필드 모델", 한국정보과학회논문지, 제 22 권 제 12 호.
1995.

[9] 정효식, 조형제, "분할된 영역의 특성을 이용한 차량번호판의 포착”, 한국정보과학회논문지, 제21권 제6호, pp.1149-1159, 1996.

[10] 황영환, 박진-우, 최환수, “자동차 번호판 자동인식에 관한 연 구”, 신호처리합동학술대회, Vol.7, pp.433-437, 1994.

[11] 신동필, "차량 자동인식 시스템의 개발에 관한 연구”, 시스템 공학연구소, 1991.

[12] N. A. Khan et. al., "A License Plate Recognition System," Proc. Intl. Conf. on Applications of Digital Image Processing XXI, pp.14-24, 1998.

[13] J. R. Cowell, "Syntatic Pattern Recognizer for Vehicle License Plates," IEEE Transactions on Vehicular Technology, Vol.4, No.4, pp.790-799, 1995.

[14] H. A. Hrgt, et. al., "A High Performance License Plate Recognition System," Proc. IEEE Intl. Conf. on Systems, Man and Cybernetics, Vol.5, pp.4357-4362, 1998.

[15] L. Fausett, Fundamentals of Neural Networks, Addison Wesley Publishing COmpany Inc., 1989.

[16] Ramesh Jain, Rangachar Kasturi, Brian G. Schunck, Machine Vision, McGraw-Hill, 1995.

[17] Milan Sonka. Vaclav Hlavac, Roger Boyle, Image Processing, Analysis, and Machine Vision, Brooks/Cole Publishing Company, 1999.

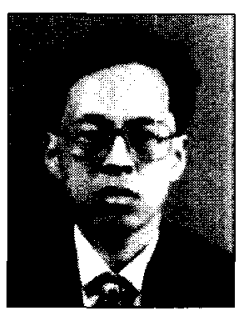

\section{장 승 주}

e-mail : sjjang@dongeui.ac.kr

1985 년 부산대학교 계산동계학과(전산학) 학사

1991년 부산대학교 계산통계학과(전산학) 석사

1996 년 부산대학교 컴퓨터공학과 박사

1987년 1996년 한국전자통신연구원 시스템 S/W연구실

1993년 1996년 부산대학교 시간강사

2000년 2002년 Lniversity of Missouri at Kansas City, visiting professor

1996년 현재 동의대학교 컴퓨터공학과 부교수

관심분야 : 운영체제, 분산시스템, Active Network, 시스템 보안

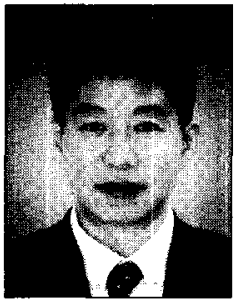

\section{신 병 철}

e-mail : shinbc@dongeui.ac.kr

1984년 연세대학교 세라믹공학 학사

1986년 KAIST 재료공학 석사

1988년 KAIST 재료공학 박사

1988년 1996년 포철 RIST 신소재연구부문 책임연구원

1996년 현재 동의대학교 신소재공학과 부교수

2001년 현재 동의대학교 전자세라믹스연구센터 소장

관심분야: 정보통신 신소재, 정보통신, 신소재 